\title{
Admission to Selective Schools, Alphabetically
}

\author{
Štěpán Jurajda and Daniel Münich \\ CERGE-EI
}

November 5, 2007

\begin{abstract}
One's position in an alphabetically sorted list may be important in determining access to oversubscribed public services. Motivated by anecdotal evidence, we investigate the importance of the position in the alphabet of Czech students for their admission chances into oversubscribed schools. Empirical evidence based on the population of students graduating from secondary schools and applying to universities is consistent with the use of alphabet in admission procedures at both secondary and tertiary level. A simple student-school matching model suggests that the repeated use of such admissions implies potential efficiency losses.
\end{abstract}

JEL Codes: H49, J78, I29

Keywords: Admissions, Alphabetical order, Serial position, Order effects

Acknowledgements CERGE-EI is a joint workplace of the Center for Economic Research and Graduate Education, Charles University, and the Economics Institute of the Academy of Sciences of the Czech Republic. Both authors are Research Affiliates at CEPR, London; Jurajda is also Research Fellow at IZA, Bonn. The help of Petr Matějů and Jindřich Krejčí from the Sociological Institute of the Czech Academy of Sciences and Vladimír Burda (formerly of the Czech National Institute of Technical and Vocational Education) in acquiring and processing the Sonda Maturant data is gratefully acknowledged, as are comments from Peter Katuscak and Peter Orazem. We also thank Ondřej Šteffl and Petr Vagenknecht of Scio for access to the National Comparative Exam data. This research has been supported by the Grant Agency of the Czech Republic (grant No.403/03/340) and a grant from the CERGE-EI Foundation under a program of the Global Development Network. All opinions expressed are those of the authors and have not been endorsed by CERGE-EI or the GDN.

Address CERGE-EI, Charles University Prague and Academy of Sciences of the Czech Republic, Politickych veznu 7, Prague 11121, Czech Republic. E-mail: stepan.jurajda@cerge-ei.cz, daniel.munich@cerge-ei.cz 


\section{Introduction}

Sorting based on 'alphabetical order' is a fact of everyday life. Team members are listed in this order, including coauthors of scientific papers; students may be seated in classroom according to their last name initials' position in the alphabet; competing firms are displayed alphabetically in phone and other directories. Could this systematic and omnipresent sorting provide an advantage to those positioned high in the alphabet? This question is often the object of popular discussions. ${ }^{1}$ Customers may choose their service provider from the top of an alphabetically sorted directory; students seated in front rows of classrooms may achiever higher learning outcomes; employers using the apparently non-discriminatory alphabetical order may be more attentive to job applicants who are interviewed first; there may be citation bias against authors whose last names begin with letters that occur late in the alphabet, etc. Yet, so far there is little evidence on the issue, thanks in large part to lack of data with individual initials. ${ }^{2}$

The question of non-discriminatory sorting is particularly important when allocating a prize or distributing a rationed good or oversubscribed public service. Consider, for example, musical competitions, which have been shown to determine life-time career success of professional musicians. Even though the goal of such (blind) competitions is to reflect the quality of each player, van Ours and Ginsburgh (2003) show that the (randomly assigned) order in which musicians play in a competition has a strong effects on their success. In this paper, we study another allocation mechanism, which is also supposed to reflect only the quality of applicants (contestants), but where sorting may also play an important role. The allocation mechanism we consider affects entire population cohorts: we focus on students' access to oversubscribed secondary schools and

\footnotetext{
${ }^{1}$ For example, The Economist (2001) suggests such effect may be present in politics by pointing out the high fraction of U.S. presidents and U.K. prime ministers with last names sorted high in the alphabet.

${ }^{2}$ The major exception are studies of citation bias; see, e.g., McCarl (1993), Einav and Yariv (2006) or Praag and Praag (in press).
} 
universities. Specifically, we ask whether students with last names sorted high in the alphabet enjoy higher chances of being admitted to selective high-quality schools. We find affirmative evidence at both secondary and tertiary level.

Even if unequal access to quality education can have serious consequences for life-time labor market outcomes, alphabetical sorting could be defended when used to randomize access among equally talented applicants in face of capacity constraints. However, using a stylized model of student-school matching we suggest that the repeated use of alphabetical sorting at entry to both secondary and tertiary education can lead to efficiency losses. We use the estimated effects from our empirical analysis to quantify these losses within a calibrated version of the model.

Our analysis is based on the experience of students in the Czech Republic, which provides a useful case to study for three reasons. First, studying alphabetical sorting effects in admission procedures in the Czech Republic is motivated by several pieces of anecdotal evidence. We know of cases where lists of applicants with multiple student characteristics (including test scores) prepared for admission committees are sorted according to the alphabet. When applications are evaluated based on multiple criteria in absence of a clear summarizing measure, marginal cases at the top of such list may obtain a more favorable treatment compared to marginal applicants toward the bottom of the list where constraints on total number of possible admissions become more binding. A similar effect could be present in those universities, which use an oral exam and call applicants to these exams in alphabetical order. ${ }^{3}$ Finally, in some cases Czech universities openly use the alphabetical order to break ties among applicants with identical admission test scores. We quote from the official specification of the admission procedure at one department of Charles University Prague, a prestigious local university: "After sorting applicants based on test score, the first 30 will be admitted (should more applicants reach the same test score level, the list will be sorted

\footnotetext{
${ }^{3}$ Such practice is currently used, e.g., at the Philosophical Faculty of Charles University Prague.
} 
alphabetically based on last name initial)." 4

Second, the reliance on alphabetical sorting in admission procedures can only be of importance in a highly selective schooling system, where student rationing is extensive. The Czech Republic is a case in point as it features a highly selective admission process at both secondary and tertiary schooling level, and thus provides a good example of the many European selective education systems. ${ }^{5}$ At $12 \%$, the country has one of the lowest tertiary attainment rates in the OECD (OECD, 2004) and students entering the university system typically come from selective academic secondary programs serving less than $15 \%$ of each cohort of secondary-school students. Tuition-free public universities provide the bulk of tertiary education and they tend to reject about a half of applicants each year. In 1999 - the year our data come from - $55 \%$ of all applicants to Czech universities were not able to enroll in any program. In contrast, almost $70 \%$ of the applicants who graduated in the same year from the selective academic secondary programs did manage to enter a university.

Third, there is unique administrative data available on study achievement and university admission experience of the whole population of Czech secondary-school graduates in 1999. Specifically, we observe national school-leaving-exam test scores from mathematics and the native Czech for all graduates from secondary programs, together with their initials. ${ }^{6}$ For all of these high-school graduates, we also see which universities they apply to, together with the admission decision.

To provide a framework for our analysis, we build a simple model of student-school matching. Students' ability is key among the admission criteria used in selective schools, but alphabetical

\footnotetext{
${ }^{4}$ The announcement, in Czech, was originally posted at http://prijimacky.ff.cuni.cz and is now available at http://home. cerge.cuni.cz/munich/alpha1.html.

${ }^{5}$ Admission standards for tertiary education are applied in Belgium, Denmark, Germany, and the Netherlands. Stricter admission standards are used in the UK, Sweden and in some of the French universities. See Jacobs and van der Ploeg (2006).

${ }^{6}$ We do not observe students graduating from the majority of apprenticeship programs, which do not lead to a school-leaving exam and do not send students to universities.
} 
sorting is allowed to play a role for admission of marginal applicants in over-subscribed schools. Marginal applicants are those with a similar admission test score on the margin of admission. There is a group of marginal applicants thanks to either noisy admission exams or discrete support of the admission 'score' measure. If only a part of the marginal group can be admitted due to capacity constraints, alphabetical sorting is invoked, either overtly or covertly.

The model implies that in presence of alphabet-based admission practices at selective schools, students admitted to such schools with last names in the bottom part of the alphabet should on average have higher ability and that this sorting should be stronger in more selective schools. Next, we note that the presence of such alphabet-ability sorting in selective high-school programs, which prepare students for university education, has consequences for college admissions. Among marginal university applicants, a 'Z' applicant from a selective high school is likely to be of higher ability compared to an 'A' applicant from the same program and this information should be used to improve the efficiency of student-school matching.

Our empirical analysis starts with the national study-achievement tests administered to the population of Czech students graduating from secondary schools in 1999. We find evidence consistent with the model predictions: 'Z' students perform better in tests compared to 'A' students and this sorting is stronger in more selective schools, suggesting that selective secondary programs use alphabetical sorting in their admissions. Next, we study the success of student applications to universities. We find a significant effect of one's last-name-initial position in the alphabet on admission chances of marginal applicants. Throughout the empirical analysis we also test for the importance of the alphabetical position of the first-name initial, thus providing a natural check on our main results. It is reassuring that we do not find the first-name-initial position in the alphabet to play any important role.

One could argue that if schools select among applicants of similar ability based on the alphabetical order, it is only one of many alternative random justifiable ways of rationing. However, 
our model implies that the use of alphabet-based sorting at both secondary and tertiary level is likely to lead not only to distributional but also efficiency consequences. We conclude the paper with a calibration exercise aimed at quantifying the extent of inefficient matching of students with universities and find that the efficiency loss is likely to be small.

The paper is organized as follows: We describe the Czech education system and our student data in Section 2, where we also outline our theoretical framework and testing strategy. Sections 3 and 4 present the test-score and college-admission analysis, respectively. The calibration exercise is presented in Section 5, while some tantalizing wage analysis based on a 1996 household survey is provided in Section 6. The last section summarizes our findings.

\section{The Czech Education System and our Data}

In this section, we describe our data in more detail and use them to offer several stylized facts about the Czech education system. Although the structure of the Czech educational system parallels those of other European countries, it differs in the relative magnitude of education provision across specific degrees and school types: the secondary school completion rate is very high, but only a small proportion of the Czech population has completed university education. After the collapse of communism in 1989, total enrollment in Czech public colleges doubled, ${ }^{7}$ but college-program completion rates decreased and, given the large size of cohorts graduating from secondary schools during the 1990s, the tertiary attainment rate of the Czech population aged 25-34 remains starkly low at about $12 \%$ as of 2002 (OECD, 2004).

The low tertiary attainment rate is not surprising given that a major group of secondarylevel students attends apprenticeship programs, which offer dismal prospects of continuing on to higher education degrees. Most of the apprenticeship programs do not lead to a school-leaving

\footnotetext{
${ }^{7}$ All of the universities in our data are public and tuition-free. Enrollment in private colleges emerged only after 1999. Even today, private tuition-based tertiary education remains miniscule in the Czech Republic.
} 
comprehensive examination, 'Maturita' in Czech, which is a pre-requisite for tertiary education. These exams, administered at the end of most four-year secondary programs are prepared by each school individually based on national guidelines; they approximately correspond to the U.K. General Certificate of Secondary Education (GCSE) or the German 'Abitur' exam. ${ }^{8}$

Our data report the test scores from these school-leaving exams for all graduates from secondary programs leading to the 'Maturita' exam. For these students, we also observe which universities they apply to, even though we do not know the details of their university-specific entrance exams. Finally, we see the admission decision for each application.

\subsection{Student Test Scores in Secondary Schools}

In 1999 the first (and so-far the last) nation-wide study achievement test - a national 'Maturita' exam - was administered at all programs with the school-leaving exam. The testing, conducted independently of the traditional school-specific 'Maturita' exams, thus targeted approximately 60 percent of the entire age cohort of twelve-graders, i.e., over 100 thousand students in 1,642 schools. Exams were held simultaneously and the results were processed centrally. ${ }^{9}$

The tested students come from three types of Czech secondary 4-year programs: apprenticeship, specialized and academic. Apprenticeship programs typically focus on craft skills, while examples of specialized secondary programs include construction or nursing schools. Finally, the academic programs are typically strong in both humanities and mathematics skills and give highest value

\footnotetext{
${ }^{8}$ In terms of the OECD classification of education levels, the apprenticeship programs without a 'Maturita' exam correspond to the ISCED 2 level (and a small group of workers with ISCED 3C). These programs serve about 40\% of the cohort. Secondary-school education with 'Maturita' then correspond to ISCED 3A. All students taking the 'Maturita' exam have completed at least 12 years of education.

${ }^{9}$ While pilot testing of standardized 'Maturita' exams started in 1997, the 1999 program, called 'Sonda Maturant 99,' was the first to cover the whole population of students taking the 'Maturita' exam and was the largest school testing program administered in the Czech Republic to date.
} 
added in terms of study achievements. ${ }^{10}$

Our data provide standardized test scores (on a 0 to 100 scale) corresponding to students' mathematics skills and to their command of the native Czech as well as one foreign language. Because different students choose different foreign languages, we focus on the mathematics and Czech results. Besides test scores, the data include students' gender, school type and district identifier. A unique feature of these data is that they contain the first and last name initials of tested students. Out of the total of 105,979 tested students, we observe name initials for over 97 thousand students and among these, 91,599 have valid test scores from mathematics and Czech language tests available. We checked whether the last-name-initial distribution in the student data is similar to that based on the population register. The correlation across the two data sources in each letter's share is high (0.95). Figure 1 presents the distribution of last name initials in our data. ${ }^{11}$

Table 1 provides a summary of the test score data by school type and supports the typical ordering of study achievement with academic programs at the top and apprenticeship programs at the bottom. ${ }^{12}$ Students graduating from academic programs also have the highest chance of being admitted to highly selective universities. Further, Filer et al. (1999) show that in 1997 wages

\footnotetext{
${ }^{10}$ See Filer and Münich (2000) or Matějư and Straková (2005) for a detailed description of the Czech education system and Münich (2004) for evidence on the value added of each type of secondary schools.

${ }^{11}$ In the Czech Republic, there are no types of last names related to a history of family wealth (such as "van" or "von" names; see, e.g., Moldanová, 2004). The country is also highly ethnically homogenous, with only one sizeable minority, the Roma. There are no nationally representative studies identifying the minority members, let alone their names. We were able to compare the national last-name-initial statistics with those based on a 2002 data set of older Roma respondents collected by a Czech NGO, 'People in Need'. The Roma last-name distribution appears highly similar to the national one with a letter-share correlation of 0.76. In any case, there are very few Roma in selective Czech schools as they are very likely to end up with only the lowest level of compulsory education and, given Czech language inefficiency, are often redirected to schools for mentally handicapped children (Šimíková et al., 2004).

${ }^{12}$ The number of students reported in the table $(\mathrm{N})$ reflects all students in the data, irrespective of whether they have a valid mathematics or Czech test score.
} 
of workers with specialized degrees were about $20 \%$ higher than wages of otherwise comparable workers with apprenticeship degrees. There was a similar wage premium for those workers with academic secondary degrees who did not achieve university degrees. It is therefore not surprising that academic and specialized high schools are in high excess demand. ${ }^{13}$ We measure excess demand using the ratio of the number of applicants rejected over the number of students admitted to schools of a given type in a given district in 1998. The last row of Table 1 shows the average of this excess demand measure available for each school type in each of Czech Republic's 76 districts (NUTS-4 territorial units). ${ }^{14}$ We note that on top of the school-type related differences in over-subscription, there is also substantial school-district-specific variation in excess demand for secondary schooling due in part to the shrinking of the youth Czech population, which occurs at different rates across districts (Münich, 2004). The student admission process is governed independently by individual schools, which base their admission decision on their entrance-exam results combined with other student-background information including grades from elementary education.

\subsection{College Admissions}

Secondary-school graduates can submit an unlimited number of university applications. An application process typically consists of a written exam and in a subset of faculties includes also oral

\footnotetext{
${ }^{13}$ The total size of the academic programs has not increased sufficiently during the first post-communist decade to meet the excess demand. The Czech Ministry of Education kept strict and rather stable limits on the maximum number of students admitted to public academic programs that it would finance. A partial adjustment came from the establishment of private secondary schools in the early 1990s (Filer and Münich, 2000).

It is also important to note that there are administrative limits on the number of applications submitted by each student. These limits lead to strategic misrepresentation of preferences; they lower the observed excess demand for the most sought-after programs as students judge the low chance of admission to a general academic program against the higher admission probability of an alternative application submitted to a less selective school.

${ }^{14}$ We pool the districts falling within the capital city of Prague into one district because of the high mobility of students across districts within the city of Prague. The average district population size (excluding Prague) is approximately 100 thousand.
} 
exams. While some faculties have a common admission procedure, many departments organize their own admission tests.

We have merged the secondary-school-graduates data described above with the administrative register of individual applications to Czech universities in 1999. The college-application data report the success or failure of each individual application (whether a given student was admitted to a particular school) ${ }^{15}$ but falls short of providing faculty-specific admission test scores and does not give name initials. We therefore focus our analysis on college applicants who have graduated from secondary programs in 1999 (for whom we have available name initials as well as 'Maturita' scores) and omit those who did so earlier. Applications by such "fresh" secondary-school graduates constitute $55 \%$ of all applications and $61 \%$ of university admissions in 1999.

The merged data provide information on a total of 116,479 applications submitted by 41,486 1999-secondary-school graduates to 116 distinct faculties of Czech public universities. In total, $29 \%$ of these applications were admitted and as a result $49 \%$ of our applicants eventually did enroll in a university program. Looking across the 116 faculties our data distinguish, the fraction of applications admitted varies widely around the median of 0.29 , but is fairly low even at the 90 th percentile of average faculty-level admission probability, which equals 0.60. Hence, all universities are highly selective. ${ }^{16}$ This is not surprising given that they are tuition-free and given the strict quotas on total enrollment set by the Ministry of Education. In fact, universities are penalized for each additional student enrolled beyond the quota limit.

\footnotetext{
${ }^{15}$ The data also cover eventual enrollment, but we do not study the students' choice of schools (enrolment) for those admitted to more than one university program.

${ }^{16}$ The Czech Republic features one of the highest college/high-school wage gaps in the EU (Jurajda, 2005).
} 


\subsection{The Use of Alphabet and Testing Strategy}

What would be the consequences of alphabetical sorting in school admissions? Clearly, under the assumption that ability and last-name initials are independent and that students do not adjust their application strategy based on their position in the alphabet,${ }^{17}$ the presence of an alphabet-affected admission process would lead to a negative correlation between being admitted to selective schools and one's position in the alphabet, conditional on applying. An interesting consequence of such admission processes is that there would also be a positive correlation between ability and one's numerical position in the alphabet among students admitted to highly selective schools as well as among students enrolled in easily accessible schools. To see this point in a simple setting, suppose that students are of three ability types (high, medium, and low) and the distribution of ability is independent of one's position in the alphabet. Suppose further that all high-ability students, irrespective of their last name initial, are admitted to highly selective programs and that all of the low-ability students end up studying in the least selective programs. For the medium types, however, given the limited supply of educational services, being sorted low in the alphabet leads to lower chances of access to selective schools. Therefore, there will be a higher-than-average ability of students with last names sorted low in the alphabet within both less selective schools (thanks to medium-ability Zs) and more selective schools (thanks to medium-ability As).

To present this argument more formally and to gain further insight into the consequences of alphabet-based school admission, we build a simple model of school-student matching, in which admissions aim to select the most able applicants using noisy entrance exams. We assume that schools admit students based on an admission test score $S$, which reflects students' ability $a$ (distributed as standard normal), and that the test score $S$ has only discrete support. Selective schools are limited in the number of students they can admit such that they (directly) admit all applicants with a test

\footnotetext{
${ }^{17}$ We are not aware of any public discussion of the issue of alphabet sorting in admission procedures in the Czech Republic. It appears that neither the students nor the schools consider this issue important.
} 
score strictly above an admission threshold score $S^{T}$ and admit only a fraction of marginal applicants who scored exactly $S^{T}$ on their admission exam. The selection among marginal applicants is based on alphabetical sorting. In other words, admissions are decided using a lexicographic order on $S$ and $N$, where $N=1,2, \ldots, 26$ denotes one's position in the alphabet.

This formulation of admissions captures the essence of the alphabet-based admission mechanisms discussed in the Introduction. It corresponds exactly to the practice at those schools that openly use the alphabetical order to break ties among applicants with identical admission test scores, but it can be thought of as providing a more general description of alphabet-based admission procedures. Schools using a continuous test score may consider as marginal all those applicants falling into a confidence interval implied by the presences of measurement error in $S$ around the threshold value of the score. Such marginal applicants can be thought of as having the discrete test threshold value $S^{T}$. Similarly for applicants who appear marginal based on multiple evaluation criteria in alphabetically sorted lists or those called to oral exams in the alphabetical order.

Given that last name initials are assumed orthogonal to ability, the expected ability of a directly admitted applicant with initial $N$, denoted $\overline{a_{D A}}(N)$, corresponds to the formula for the expectation of a truncated standard normal distribution:

$$
\overline{a_{D A}}(N) \equiv E\left[a \mid S>S^{T}, N\right]=E\left[a \mid S>S^{T}\right]=S^{T}+\frac{\phi\left(S^{T}\right)}{1-\Phi\left(S^{T}\right)}
$$

and does not depend on $N$. In equation (1), $\phi$ and $\Phi$ denote the probability density and the cumulative distribution function of the standard normal distribution, respectively. The expected ability of marginal applicants, which also does not depend on $N$, can be expressed as ${ }^{18}$

$$
\overline{a_{M}}(N) \equiv E\left[a \mid S=S^{T}, N\right]=S^{T}
$$

\footnotetext{
${ }^{18}$ In Equation (1), we assume that the discrete value of $S$ corresponding to each interval of the continously distributed ability $a$ equals the lowest value of $a$ in the interval. Here, we make the simplifying assumption that the interval corresponding to value $S^{T}$ is symmetrical around $a=S^{T}$.
} 
Next, consider the alphabetically sorted list of marginal applicants and denote by $N^{T}$ the initial of the last marginal student who is admitted. The expected ability of admitted applicants with surname initial $N>N^{T}$, that is of students who are only admitted directly, equals $\overline{a_{D A}}$. For $N \leq N^{T}$, on the other hand, the school admits all marginal applicants with a given initial and the expected ability of all admitted applicants equals the average of the expected ability of direct and marginal admits, weighted by the population proportion of each group for each initial. Hence, the expected ability of all admitted students $\bar{a}$ can be expressed as follows:

$$
\bar{a} \equiv E\left[a \mid S \geq S^{T}, N\right]=\left\{\begin{array}{c}
\overline{a_{D A}}=S^{T}+\frac{\phi\left(S^{T}\right)}{1-\Phi\left(S^{T}\right)} \text { for } N>N^{T} \\
\frac{\left(1-\Phi\left(S^{T}\right)\right) \overline{a_{D A}}+m \overline{a_{M}}}{\left(1-\Phi\left(S^{T}\right)\right)+m}=S^{T}+\frac{\phi\left(S^{T}\right)}{1-\Phi\left(S^{T}\right)+m} \text { for } N \leq N^{T},
\end{array}\right.
$$

where we denote by $m$ the expected share of marginal applicants with a given initial on all applicants with that initial. We assume that the share $m$ does not change with the degree of selectivity $S^{T}$ and note that it does not depend on $N$, similar to $\overline{a_{M}}$. Equation (3) implies that the expected ability of admitted students is higher for those with $N>N^{T}$ compared to those with $N \leq N^{T}$. Clearly, different schools apply a different $N^{T}$ threshold (there is a distribution of $N^{T}$ across schools) such that the use of alphabetical sorting of marginal applicants implies a positive relationship between $N$ and $\bar{a}$ in the population of admitted students. ${ }^{19}$

Interestingly, equation (3) also suggests that the ability difference across the alphabet, denoted $\Delta^{S}$, which can be expressed as

$$
\Delta^{S} \equiv E\left(a \mid S>S^{T}, N>N^{T}\right)-E\left(a \mid S>S^{T}, N \leq N^{T}\right)=\frac{\phi\left(S^{T}\right) m}{\left[1-\Phi\left(S^{T}\right)\right]\left[\left(1-\Phi\left(S^{T}\right)\right)+m\right]}
$$

grows with the degree of admission selectivity; i.e., it is a function increasing in $S^{T}$. The expected ability gap between a ' $\mathrm{Z}$ ' student and an 'A' student admitted to a selective school is higher the more selective a given school is in admitting students. This result rests on the assumption that the

\footnotetext{
${ }^{19}$ By the same argument, there ought to be a positive ability-alphabet sorting among those not admitted to selective schools.
} 
share of marginal applicants $m$ does not depend on $S^{T}$. It would hold more generally as long as $m$ does not decrease relative to the share of directly admitted applicants $1-\Phi\left(S^{T}\right)$ as $S^{T}$ increases, that is as long as more oversubscribed schools are not disproportionately better at discriminating among applicants' ability compared to less selective programs. This would correspond, e.g., to a similar level of measurement error in admission tests of differently selective schools.

We are now ready to consider the consequences of repeated use of such admission procedures at the entry to both secondary and tertiary schools, where only students admitted to selective secondary schools can apply to universities. We further assume that skill production in secondary schools does not close the alphabet-ability gap described in equation (4). For the sake of simplicity, we assume that the ability of graduates of selective secondary schools, denoted $\widetilde{a}$, can be expressed as $\widetilde{a}=\delta \widetilde{N}+u$, where $u$ follows the standard normal distribution, $\widetilde{N}$ is an appropriate linear transformation of $N$ that guarantees that $E(\widetilde{a})=0$, and $\delta$ captures the positive dependence of the expected ability of students admitted to selective secondary schools on $N$. Following the logic provided above, and using $\widetilde{S}$ to denote test scores from a college entrance exam, the expected ability of marginal applicants to colleges is $E\left(\widetilde{a} \mid \widetilde{S}=\widetilde{S}^{T}, \widetilde{N}\right)=\widetilde{S}^{T}+\delta \widetilde{N}$. Clearly, colleges should select among the marginal applicants in reverse alphabetical order as such choice would result in higher average ability of admitted students compared to pure randomization or standard alphabetical sorting.

How can we test the predictions of this simple model of alphabet-based school-student matching? First, our data on school-leaving exams of selective secondary school graduates allow us to ask whether ' $Z$ ' students display higher ability in 'Maturita' tests compared to 'A' students as predicted by equation (3). Furthermore, we can use the substantial variation in excess demand among the 1,642 Czech secondary schools with the 'Maturita' exam (see Section 3) to ask whether the ability gap between ' $\mathrm{Z}$ ' and 'A' students is higher in more selective schools, as predicted by equation (4). Such evidence would be consistent with the use of alphabet, overt or covert, in high-school 
admissions.

Second, the information on the success of secondary school graduates in applying to universities allows us to test directly whether ' $\mathrm{Z}$ ' applicants face higher chances of being admitted to colleges compared to 'A' applicants, conditional on having similar admission test scores. We expect only marginal applicants to be affected by their alphabetical position; hence, it is important that we can use the 'Maturita' test scores to predict who is a marginal applicant. Specifically, for each faculty, we observe the list of applicants with their 'Maturita' test scores and we know the total number of admits. We use this information, together with other predictors, to identify applicants who are likely to be close to the margin of acceptance - those at the percentile of the 'Maturita' exam distribution of applicants to a particular faculty that corresponds to the share of admitted applicants to that faculty. ${ }^{20}$

\section{Test Score Analysis}

Our simple model suggests that alphabet-based admission procedures can lead to a positive correlation between ability and one's numerical position in the alphabet among students admitted to

\footnotetext{
${ }^{20}$ We would ideally like to measure the alphabetical effect on admission only in faculties (or departments) that are using alphabetical sorting in their admission procedures. Here, we face three fundamental difficulties. First, our data only tell us what faculty a given student applied to while there are often department-specific admission procedures in place. Second, the unique student data we have been able to access in 2005 comes from 1999 and schools do not keep records of admission organizational practices. Third, our preliminary testing revealed that it is often difficult to ask department or faculty officials specific questions about the use of the alphabetical order in a manner that does not reveal our research question and therefore does not lead to possibly selected response rate. Below, we therefore analyze the whole population of Czech university faculties keeping in mind that our results will reflect the likely mix of schools that do and do not use alphabet-based admission procedures.

We would also like to study the entry into secondary programs but we do not have information on student ability before entering secondary schools and do not observe applicants who were not admitted; hence, we cannot focus on the marginal applicants to secondary schools in order to ask about the alphabet's potential direct effect on secondaryschool admission.
} 
selective schools. Our test score data allow us to assess the presence of such ability-alphabet sorting among students of the most selective academic secondary programs and the less selective specialized and apprenticeship programs with a school leaving exam; we do not observe students of the least selective apprenticeship programs without 'Maturita' exams (see Section 2). ${ }^{21}$ Specifically, we regress students' test scores on their position in the alphabet using the whole sample of test scores and also by school type. Our main focus is on last-name initials, but we also include a measure of one's first-name alphabetical position as a natural check on our approach since we know of no reason why first-name initials should affect admission chances.

Next, we offer a stronger test of our hypothesis: We ask whether the relationship between alphabetical position and test scores differs across schools that differ in how over-subscribed they are, as implied by equation (4), by interacting our excess demand measure with one's position in the alphabet. There is dramatic variation in the degree of student selection across our 1,642 secondary schools: The school with the median value of excess demand rejects 19 students for every 100 admitted. In comparison, a school at the 90th (10th) percentile of the school-specific excess demand distribution rejects 43 (3) students.

We use two alternative measures of one's position in the alphabet. The simplest approach is to include the numerical position (1 to 26$)$ of one's first- and last-name initial. However, given that each letter in the alphabet represents a population group of different size (see Figure 1), a more precise measure of one's position in an alphabetically ordered list consists of the fraction of population with last (first) name initial sorted higher in the alphabet. For the sake of comparability, both measures are scaled to give one's alphabetical percentile position between 0 and 1 .

\footnotetext{
${ }^{21}$ We assume that 'Maturita' test scores reflect ability as of the time of admission. This assumption is problematic to the extent that different schools improve students' test scores differently. However, this problem is diminished when we estimate our regressions for each school type separately. Furthermore, all of our alphabet-related estimates reported below are robust to the inclusion of school fixed effects, both in terms of statistical significance and coefficient magnitude.
} 
We find that more selective schools indeed do display higher test scores (and presumably ability) for those of their students who have last names sorted low in the alphabet. Tables 2,3 , and 4 bear out this claim. Table 2 presents regression coefficients of interest from the basic mathematics-testscore regressions, while Table 3 replicates this analysis for the Czech language test scores. The two panels of each table correspond to the two measures of one's position in the alphabet. In the first column of each table, we present the name-initials coefficients estimated off the entire sample of tested students. The parameter estimates, which are not sensitive to the use of alternative measures of alphabetical position, suggest that having a last name initial sorted low in the alphabet is correlated with high test scores in both mathematics and Czech language tests. Columns (2) to (4) of each table then ask the same question separately for each school type. The data suggest a strong relationship between test scores and last-name-initial alphabetical position in the most selective schools - in the academic programs. The last-name-initial effects are not only statistically, but also economically significant: "Moving" from 'A' to ' $\mathrm{Z}$ ' increases the predicted mathematics test score in the academic programs by 2 to 2.5 points on the 0 to 100 test score scale, corresponding to a rise from the median to the 55th percentile on the score distribution. The size of the Czech-language effect is similar.

When using the population-based position measures, we obtain a puzzling negative estimate of the first-name-initial position in the specialized schools. It turns out that this negative coefficient represents the sole violation of our natural specification test as all other first-name-initial coefficients in the subsequent analysis are not statistically significant.

Finally, in Table 4 we offer the stronger test of our sorting hypothesis by interacting the school excess demand measure with one's position in the alphabet. Excess demand likely proxies for ability of admitted students and is therefore also separately controlled for in the estimated regressions. Our preferred specification, presented in the table, is one where we impose no effect of last (or first) 
name initial in schools with zero excess demand. ${ }^{22}$ There are strong positive coefficients on all of the estimated interaction terms between excess demand and last name initial position in the alphabet. The higher the extent of student selection at school entry, the stronger the test scores of those situated towards the bottom of the alphabet. In contrast, none of the first-name interactions are important. The interaction terms are stronger within the sub-sample of students of the 320 Czech academic secondary programs (in columns 3 and 4). To illustrate the size of the interaction term for the first alphabetical-position measure, consider the mathematics 'effect' of moving from 'A' to ' $\mathrm{Z}$ ' in a typical (median) academic program (with 3 students rejected for every 10 admitted) and in a highly selective program featuring a 90th-percentile student rejection rate $(5$ rejected for 10 admitted): the 'effect' is 2.0 points in the first school and 3.4 in the latter.

Overall, we find that students with surnames sorted low in the alphabet do achieve higher test scores on average and that this sorting "effect" is stronger in more over-subscribed schools. As we can think of no alternative explanation, we find these results strongly consistent with the ability-alphabet sorting hypothesis and therefore suggestive of the presence of alphabet-based admission procedures at the secondary school level. ${ }^{23}$ In the next section, we investigate tertiary-level admissions.

\footnotetext{
${ }^{22}$ In unreported regressions where we enter not only the interaction between last name initial and excess demand, but also one's last name position separately, both of the last-initial coefficients end up below conventional levels of statistical significance with the exception of a positive interaction coefficient in the mathematics regression based on the population-order measure.

${ }^{23}$ The argument that the observed alphabet-ability sorting arises thanks to admission procedures at the secondary school level is further supported by preliminary evidence of the presence of no alphabet-ability sorting among students graduating from primary-level programs, that is before admission to secondary schools. Specifically, we regressed mathematics and Czech language test scores of 9,625 students in the 9th grade of elementary schools on their last name initial position in the alphabet and found no statistically or economically significant coefficients. The data come from the 'National comparative test', which is conducted by Scio.cz, a private testing agency, and which recently became widely used by secondary schools as admission exam. The sample corresponds to students who took a practice test under certified conditions in 2005 .
} 


\section{College Admission Analysis}

Our population registry of college applications and admissions allows us to test directly for the effect of one's position in the alphabet according to last name initial on one's chances of being admitted to over-subscribed colleges. Our hypothesis is that alphabetical sorting plays a role only for applicants on the margin of admission. Therefore, we would ideally like to identify marginal applications using scores from admission exams administered independently by each department or faculty. In the absence of this information, we predict admission probabilities for each application at each faculty using students' 'Maturita' test scores, which help us control for student ability, and using the average success rate in college admission of all students from a given secondary school, which helps us control for school-quality and reputation effects. In addition, we also use students' gender and age to predict admission chances. Note that we observe the complete pool of applications for each faculty such that the identification of marginal applications is also schoolspecific. We can therefore test for the effect of the alphabet on admission decisions in different parts of the distribution of predicted admission chances, which is an important part of our overall testing strategy. Our hypothesis is that the 'alphabetical' effect is present only for those applications in the central part of such faculty-specific distribution, i.e. for those who are neither highly likely nor highly unlikely to be admitted to a given faculty.

We proceed in two steps. First, we estimate admission probability equations separately for each of the 116 distinct faculties of Czech public universities. The success of individual applications is captured using linear probability models controlling for the student and school quality measures described above. ${ }^{24}$ Next, we assign each application a within-faculty percentile ranking according to its predicted probability of admission. Such percentile rankings are comparable across schools

\footnotetext{
${ }^{24}$ The two test scores and the school average success are positive and statistically significant in the vast majority of these school-specific regressions. The analysis in this section is not materially affected by using a Logit specification in place of the linear model.
} 
in the sense that they allow us to separately analyze groups of applications that are close to the admission margin or are very likely or very unlikely to be admitted. (Note that the average predicted probability of admission is equal to the ratio of admitted students to all applications to a given faculty. Hence, the median predicted probability corresponds to the margin of admission.)

In the second-step, we re-estimate the admission equation, this time on the pooled sample of applications to all faculties/universities. This pooled specification controls for one's position in the alphabet and is estimated separately for different parts of the percentile ranking distribution. Using this second-step regression, we can ask about the predictive power of one's position in the alphabet on admission chances of applications that are likely to be in (above, below) the marginal-acceptance group. We do not include our applicant quality measures in the second-stage regression, but we additionally control for the overall level of excess demand at a given tertiary school. ${ }^{25}$

An important aspect of our specification choice is how we control for one's position in the alphabet. As in Section 2.1, we use two simple measures, one based on the numerical position (1 to 26) of one's first- and last-name initial, the other reflecting the fraction of population with last (first) name initial sorted higher in the alphabet. However, to the extent that school-specific groups of applications do not closely mimic the population-wide alphabetical structure, one should also construct an alphabet-position measure separately for each school-specific pool of applications. To asses the importance of such measurement error, we compare results based on all three types of measures, all scaled to be between 0 and 1.

Table 5 shows the complete set of second-stage coefficients of one's position in the alphabet, both in terms of first and last name initial. The three horizontal panels distinguish between the three different types of position measures we use. Each column corresponds to a different part of

\footnotetext{
${ }^{25}$ Our college excess demand measure is the ratio of rejected to accepted applications. It helps to predict admission chances and it could not be used in the faculty-specific first-stage regressions. We enter this measure as a step function corresponding to quantiles of school-specific excess demand.
} 
the predicted admission probability distribution: the first column gives estimates of interest based on the complete sample of all applications. Column (2) then provides alphabetical parameters from regressions based on the sub-sample of applications which fall below the 40th percentile of schoolspecific predicted admission chances. Next, columns (3) and (4) correspond to percentile ranges 40-60 and over 60, respectively. Our hypothesis is that marginal cases (those in the middle of the predicted admission distribution) should be affected by one's last-name initial but not first-name initial.

It is clear that there is a statistically significant negative effect of being sorted low in the alphabet on admission chances for those applications that are close to the center of the predicted admission distribution. ${ }^{26}$ The results are robust to the use of alternative alphabetical-position measures and they are also not sensitive to additionally conditioning on applicants' quality controls (student 'Maturita' scores and secondary school average success rates) in the second stage (these results are available upon request). Finally, in none of the estimated specifications did the first-name initial position play any role, which is reassuring for our interpretation of the estimates.

The size of the effect implies that among marginal applications, moving from $\mathrm{A}$ to $\mathrm{Z}$ reduces admission chances by over 2 percent. This is not a negligible effect, especially given that it likely reflects a mix of schools which do and do not use alphabetical sorting in their admission procedures. For comparison, increasing one's 'Maturita' mathematical test score by one standard deviation leads to increasing the admission chances by 1 percent. ${ }^{27}$

\footnotetext{
${ }^{26}$ Statistical inference is only little affected by the clustering of unobservables at the level of last-name initial, motivated by the grouped level of variation in this regressor; we obtain qualitatively similar results when clustering at the level of individual students, which reflects the likely correlation of unobservables across applications submitted by the same student. We also note that the reported standard errors for the first-name initial are also clustered at the last-name initial level and are thus not correct. A more conservative (and in this case unnecessary) approach would be to base first-name-initial inference on re-estimating each specification with first-name clustering.

${ }^{27}$ Both the standard deviation and the coefficient estimate of the mathematical test score correspond to the 22,890 applications in the 40-60 range.
} 
Our choice of the 40-60 percentile range is obviously arbitrary. We have therefore re-estimated the second-stage regression (with the most detailed third alphabet position measure) for a set of double-decile (moving) windows in predicted percentile position. We display the estimated lastname-initial coefficients in Figure 2. It is clear that the negative impact of last-name initial is strongest in the middle of the predicted admission-chances distribution, i.e. for the marginal cases, while it is close to 0 both for those applications that are very likely and those that are very unlikely to get accepted.

We have conducted several additional sensitivity checks (using the third, most detailed measure of one's position in the alphabet). First, we noted that the second step of our analysis, based on all individual applications, implicitly weights school-specific admission practices by the size of each school-specific pool of applications. This is an optimal strategy to the extent that the first-stage faculty-specific prediction regressions, which we use to identify marginal applications, are more precisely estimated for larger application groups. As a robustness check, we have re-estimated the second-stage regressions for the marginal applications using 100 cases on each side of the median predicted admission probability of each school. This way, we work with approximately the same number of marginal applications as in column (3), but each faculty has the same weight in the regression. We again obtained a statistically significant last-name-position coefficient of -0.022 and an insignificant parameter estimate for the first-name initial position.

We have also alternatively identified marginal applications using a range based not on the percentile ranking of applications, but based on the predicted probabilities of admission themselves. Specifically, we have re-estimated our second-stage regression on the sub-sample of $35,213(18,179)$ applications with predicted admission chances ranging within $0.1(0.05)$ of the average predicted probability at each school. We have again obtained small and insignificant first-name coefficients while the last-name parameter was $-0.013(-0.020)$ with a corresponding $p$ value of $0.08(0.02)$. In sum, it appears that the main finding is very robust to the way we identify the marginal group of 
applications. $^{28}$

Finally, in order to illustrate the importance of the so-far maintained parsimonious linear-effect assumption, we have also estimated the second-step regression with a step function in last-name initial. In Figure 3 we present the step-function coefficients estimated off the 40-60 predictedadmission-probability percentile region and therefore corresponding to the linear coefficient of -0.026 in column (3) of Table 5. While there are strong 'spikes' for specific letters, the displayed pattern is broadly consistent with the linear-effect assumption. ${ }^{29}$

Overall, the evidence is consistent with the presence of a significant negative effect of being sorted low in the alphabet on admission chances of marginal applicants to colleges, similar to our findings based on secondary schools.

\section{$5 \quad$ Efficiency Loss Calibration}

We now return to our simple model of Section 2.3 to interpret the evidence suggesting that being sorted low in the alphabet leads to a disadvantage when trying to enter selective secondary as well as tertiary programs. The model suggests that in presence of noisy admission exams, tertiary schools should choose 'Z' marginal candidates over 'A' marginal applications, i.e., apply reverse alphabetical ordering, because of the alphabet-ability sorting present among graduates of selective secondary

\footnotetext{
${ }^{28}$ We have also separately estimated our specifications using the third, most detailed position measure for the Philosophical Faculty of Charles University - the faculty, which openly features alphabet-based tie-breaking practices. Using all 2,962 applications we obtain a large negative last-name initial coefficient of -0.037 with a corresponding $p$ value of 0.028 . This coefficient becomes somewhat smaller as we "zoom in" on the marginal applications, but remains above the population-wide estimates presented in this Section. The first-name coefficients estimated for this particular faculty are invariably small and statistically insignificant.

${ }^{29}$ Replacing one linear term with 25 dummy variables increases the R2 of the regression very little: from 0.1820 to 0.1829. Figure 3 may also suggest a special role for the first three letters (A, B and C); however, introducing a dummy variable for the first three letters into the regressions in column (2) results in an insignificant dummy coefficient and affects neither the magnitude nor the significance of the last-name-initial linear coefficient.
} 
programs. In contrast to this efficiency prescription, our evidence suggests that both secondary and tertiary schools use the alphabetical order in the same standard fashion. We therefore ask whether, given the magnitude of our estimates, alphabet-based admission procedures could have sizeable efficiency consequences in a country, where students are subject to repeated selective screening into higher levels of education. To this effect, we calibrate and simulate the model of Section 2.3. Our measure of efficiency corresponds to the ability of colleges to select the most able applicants.

Our first task is to generate a simulated population of students of selective academic secondary schools that displays the same magnitude of alphabet-ability sorting that we recorded in Tables 2 and 3. We follow the descriptive statistics presented in Table 1 to generate a population of 26,000 applicants to these academic programs. The simulated applicant population displays the same distribution of surname initials as observed in our data (see Figure 1). We assign each applicant $i$ an ability index $a_{i}$ drawn from the standard normal distribution. We set the admission threshold for direct admits at the 30th percentile of the ability distribution $a$ and identify those between the 20th and 30th percentile as marginal applicants. This ensures that the simulated excess demand ratio matches the observed selectivity of these secondary programs ${ }^{30}$ and that we generate the "right" number of admitted students. We therefore directly admit the top $70 \%$ of applicants and consider as marginal the following decile group. Marginal applicants are admitted if their alphabetical position according to last name initial is above a randomly drawn position (integer) $r_{i} \in\{1,2, \ldots 26\}$, i.e., when $N_{i} \leq r_{i}$ using the alphabetical position notation of Section 2.3. The random draw of $r$ corresponds to different schools using a different threshold initial for marginal admissions. Finally, we normalize the mean and the standard deviation of the ability distribution of admitted students to mimic the observed statistics reported in Table 1 and regress this measure of ability on the last name initial alphabetical position of admitted students. We obtain parameter estimates that are

\footnotetext{
${ }^{30}$ In effect, 25 applicants are rejected out of each 100 applicants, which results in an excess demand measure (the ratio of rejected to admitted) consistent with the value of 0.31 listed in Table 1.
} 
similar in magnitude to those reported for academic secondary programs in Tables 2 and 3. Our simulation therefore successfully mimics the empirical magnitude of the alphabet-ability sorting in secondary schools, despite its many simplifying assumptions.

In the second step, we focus on college admissions. We assume that all of the students admitted to academic secondary programs in the first step of our simulation choose to apply to university after graduating. We also simulate another, similarly sized group of university applicants consisting of graduates of the specialized (technical) secondary schools. We allow only half of all of these applicants to be successful. ${ }^{31}$ The ability distribution of the students of academic secondary programs at the time of graduation is generated as the sum of the ability $a$ at admission (as of four years earlier) and a normally distributed noise with zero mean and standard deviation equal to that of the $a$ distribution. This additional independent noise is meant to reflect the many additional determinants of students' skills that are at work during the 4-year secondary programs. We also generate the (normal) ability distribution of applicants from specialized technical schools without any alphabet sorting effects, in accordance with the parameters of Tables 2 and 3.

We are now ready to simulate college admissions as follows: the top $45 \%$ of applicants (from both academic and specialized secondary programs) are admitted directly while those in the 45-55 percentile range are considered marginal, consistent with the mechanism we applied for secondaryschool admissions. Finally, we admit marginal applicants based on the alphabetical order in the same fashion that we used for simulating secondary-school admissions. To see whether the simulated 'alphabetical' effect on admission of marginal students is similar in size to that we observed in our data, we regress the college admission outcome from the simulation on the alphabetical position of applicants; we do so only for the marginal students, which now corresponds to those in the 40-60

\footnotetext{
${ }^{31}$ This corresponds to the half of all applicants from all secondary schools with the 'Maturita' exam who manage to enrol in a university (see Section 2.2). We abstract from the fact that secondary-school graduates can apply to several universities but enrol in only one when admitted to more than one.
} 
percentile range, in line with the empirical evidence presented in Figure 2. We obtain a coefficient, which is an order of magnitude larger than that reported in Table 5. In order to reconcile our simulation with the empirical estimates, we therefore deduce that only $10 \%$ of Czech universities uses alphabetical sorting in their admissions. Here, the simulation is providing us with a formalized guess of the fraction of university faculties that use sorted lists of applicants or cut ties using the alphabetical order. ${ }^{32}$ We further assume that the other $90 \%$ of college admissions select marginal students at random.

We are now ready to quantify the extent of admission inefficiency for marginal college applicants from academic secondary schools. First, in the $10 \%$ of faculties that use the alphabetical order as the mechanism for admitting marginal applicants, we replace it with the reverse alphabetical order, following the prescription of the theoretical model. We find that the admission outcome under these two different selection rules differs in $70 \%$ of the cases. Second, we use the reverse alphabetical order in place of the random selection at the remaining $90 \%$ of faculties, which results in different admission results for $50 \%$ of marginal applicants. Summing up, we conclude that using the reverse alphabetical order would improve matches for $52 \%$ of marginal applicants from academic secondary programs. Given that marginal admits form about one fifth of all admitted college students in our simulation and that only half of marginal applicants come from the academic secondary programs, we conclude that the repeated use of the alphabetical order may lead to inefficient school-student matches for about $5 \%$ of students admitted to Czech universities. This is not a large effect, which is not surprising given that only marginal university applicants from a subset of secondary-schools are affected. Nevertheless, our analysis illustrates the potential for efficiency losses from the repeated use of the same order for allocating rationed public services.

\footnotetext{
${ }^{32}$ Recall that it is not possible to find out which faculties used alphabetical sorting in 1999.
} 


\section{Wage Analysis}

An interesting question related to our analysis of school admissions is whether the consequences of the use of alphabetical order in admission procedures can also be detected in labor-market outcomes of the adult population. In particular, our sorting hypothesis implies that one's position in the alphabet is correlated with one's ability within groups of workers defined by the degree of selectivity of their schooling (within group, those workers with last-name initial high in the alphabet should have lower ability). ${ }^{33}$ This obviously depends on the extent to which wages reflect ability and also presumes the existence of alphabet-based admission procedures in history - affecting all age groups in the labor force.

To provide tantalizing evidence on this question, we use retrospective survey data collected from over 3 thousands Czech households in December 1996. The data is unique in that it reports name initials of surveyed individuals. ${ }^{34}$ We note that while our education-attainment analysis is based on detailed administrative population data, our wage sample is small and likely affected by nonresponse and wage misreporting. ${ }^{35}$ Our wage analysis focuses on males because of the complications that marriage (change of last name) brings to the analysis of adult females' alphabetical position on

\footnotetext{
${ }^{33}$ Whether one's position in the alphabet is a predictor of wages on average, beyond its effect through educational attainment, is a more complicated question. If wages rise with ability the same way for workers with different education degrees, one would not expect any average wage effect of the alphabet after controlling for educational attainment.

${ }^{34}$ The sample of 3,157 households is representative of the 1996 Czech population. These data have been used in, e.g., Münich et al. (2005) and we refer the reader to the more detailed data description provided there.

${ }^{35}$ Focusing on wages, we ignore the potential effect that one's position in the alphabet has on participation, both directly through a potential effect on hiring (from a sorted list) and indirectly through schooling attainment. This omission is driven by our household survey data where distinguishing unemployment from being out of the labor force is difficult. We also do not report estimates of the direct effect that one's position in the alphabet could have on educational attainment. Our college-admission analysis points out that the alphabetical order matters only for marginal applicants. Similarly, our secondary-school analysis highlights that alphabetical effects are strong in only a subset of the schools. Hence, it is unlikely that there would be an average effect on educational attainment. Indeed, we are unable to estimate any alphabet-related parameters with any degree of precision using our household survey.
} 
labor market outcomes. ${ }^{36}$ The wage measure consists of a monthly gross salary adjusted for daily hours worked. We observe 1,852 employed male workers aged 16 to 60 in 1996. The mean log CZK (Czech Crown) monthly wage rate is 8.86 .

Our approach is to estimate simple log-wage regressions where in addition to standard Mincerian controls (education and a quadratic in potential experience and a dummy for the capitol city of Prague), we also condition on two name-initial variables indicating one's position in the alphabet. We again rely on two alternative measures: (i) the numerical position (1 to 26$)$ in the alphabet of one's first and last name initial (normalized to be between 0 and 1), and (ii) the fraction of the population with first or last names sorted higher in the alphabet for each worker.

The alphabet-ability sorting hypothesis presented formally in Section 2.3 implies a positive "effect" of the alphabet on ability (and hence wages) within both highly and least selective schools. Given the small size of our wage data, however, we cannot afford to separately estimate our wage regression for detailed school types. The simplest approximation of school type, related to the degree of student selection, is to distinguish between the highly selective academic secondary programs combined with universities and all other education programs (elementary, apprenticeship and specialized). We follow this division in Table 6, where column (1) refers to estimates based on all of our wage observations, while columns (2) and (3) divide the sample based on education type.

Although the estimates based on the small group of workers with selective education in column (3) are very noisy, we find a positive last-name-initial coefficient in column (2) for workers with less selective education. The coefficient based on the more precise alphabet position measure is significant at the $10 \%$ level using robust standard errors. ${ }^{37}$ The parameter estimate implies a $5.2 \%$

\footnotetext{
${ }^{36}$ We compared the last-name initial distribution from our wage data to that derived based on the population register. The correlation of each letter's share in the Czech population and our sample is 0.96. We conclude that the omission from our sample of males who did not engage in any employment in our sample frame does not affect the 'alphabetical' composition of our data.

${ }^{37}$ However, applying the more appropriate (conservative) clustering of residuals at the level of 26 last name initials,
} 
wage increase associated with 'moving" from ' $\mathrm{Z}$ ' to 'A' among workers with lower education, which is an effect almost identical to the benefit of a year of education estimated on the whole sample of 1,852 workers. ${ }^{38}$ Again, the first-name-initial coefficients never reach even marginal levels of statistical significance. $^{39}$ The wage sample corresponding to graduates from selective programs may be too small, at 285 observations, to detect alphabetical sorting effect. Overall, we find our wage-structure estimates to be somewhat supportive of the ability-alphabet sorting prediction.

\section{Conclusions}

While economists have explored the labor-market effect of racial attributes of first names (Bertrand and Mullainathan, 2004; Fryer and Levitt, 2004), studied the socio-economic impact of uncommon surnames (Collado et al., 2007; Güell et al., 2007), and asked about the incidence of women changing their surname at marriage (Goldin and Shim, 2004), no attention has been paid so far to potential effects stemming from the widespread use of the alphabetical order.

In this paper, we are fortunate to access unique administrative data that report name initials. We find evidence highly suggestive of the use of the alphabet in admission policies of Czech secondary and tertiary schools. Among students admitted to the most selective secondary schools, those

the $\mathrm{p}$ value on this coefficient increases from 0.092 to 0.120 .

${ }^{38}$ The finding in Section 3 of no alphabet-ability sorting effects in less selective secondary programs with 'Maturita' exam does not contrast with the results of the wage analysis. The group of workers from less selective schools who report wages in the household survey consists primarily of apprentices who graduated from programs not offering the school-leaving 'Maturita' exam - that is graduates of the least selective secondary programs. The finding of the presence of alphabet-ability sorting among graduates of the most selective schools (academic high schools and colleges) combined with the finding of little such sorting in (technical) secondary programs with average selectivity levels would imply the presence of such sorting in the least selective programs, i.e., for apprentices without the 'Maturita' exam.

${ }^{39}$ As a further robustness check, we have estimated our specifications on the sample of employed married women. Marriage and name change should render the effect of one's last name smaller and possibly insignificant. Indeed, none of the (unreported) female 'alphabetical' coefficients we obtained reached even marginal levels of statistical significance. The sample of employed single women was too small (at 340) to allow for effective estimation. 
sorted low in the alphabet achieve higher test scores and presumably have higher ability. Among university applicants predicted to be close to the non-admission margin, those high in the alphabet enjoy higher chances of admission. These findings are robust to the use of different measures of one's position in the alphabet and also stand our natural test of asking about the effect of one's first-name-initial position in the alphabet, which we find to play no role. There is also some evidence that conditional on low education attainment, i.e. not being admitted to higher school levels, wages (and presumably ability) are higher for workers sorted low in the alphabet.

This set of findings can be explained by a simple model of school admission with students of three ability types (high, medium, and low) distributed independently of last name initial, where all high-ability and none of the low-ability students are admitted to selective schools, and where admission of medium-ability types is decided in a way affected by alphabetical sorting. We do not provide direct evidence of the various possible ways an alphabetical 'treatment' may be taking place in schools' admission policies. Yet, we believe that the combination of our findings and the absence of an alternative explanation lend our hypothesis substantial credibility.

Should our interpretation of the empirical findings be correct, there would be a non-negligible negative effect of apparently non-discriminatory practices for individuals with last names towards the bottom of the alphabet. Rationing of public services based on a lottery can be optimal, but the use of a fixed "lottery ticket" (one's last name initial) throughout many lotteries (many schooling levels) is not fair and may even have efficiency consequences, as we illustrate using a calibrated simulation based on our school-student matching model. A simple remedy is to assign each application a numerical code at random and base sorting on this alternative lottery. We believe that our results motivate future research into the use of alphabetical listings in public decision making. For start, selective education programs are a feature of many European countries other than the Czech Republic. 


\section{Bibliography}

Bertrand, M., and S. Mullainathan (2004) "Are Emily and Greg More Employable than Lakisha and Jamal? A Field Experiment on Labor Market Discrimination," American Economic Review 94 (4), pp. 991.

Collado, M. Dolores, Ortín, Ignacio Ortuño, and Andrés Romeu (2007) "Surnames and social status in Spain," mimeo, Universidad de Alicante.

The Economist (2001) "As easy as ZYX," Vol. 360, No. 8237: p.13.

Einav, L., and L. Yariv (2006) "What's in a Surname? The Effects of Surname Initials on Academic Success" Journal of Economic Perspectives Vol. 20, No. 1: 175-188.

Filer, R., Jurajda, S̆., and J. Plánovský (1999) "Education and Wages in the Czech and Slovak Republics During Transition," Labour Economics, 6 (4), 581-593.

Filer, R., and D. Münich (2000) "Responses of Private and Public Schools to Voucher Funding: The Czech and Hungarian Experience," CERGE-EI Working Paper No. 160.

Fryer, R., Jr. and S. Levitt (2004) "The Causes and Consequences of Distinctively Black Names," Quarterly Journal of Economics 119 (3), pp. 767.

Goldin, C., and M. Shim (2004) "Making a Name: Women's Surnames at Marriage and Beyond," Journal of Economic Perspectives 18, 2(1), pp. 143-160.

Güell, Maia, Rodríguez Mora, José V., and Chris Telmer (2007) "Intergenerational Mobility and the Informative Content of Surnames," mimeo, Universitat Pompeu Fabra.

Jacobs, B., and F. van der Ploeg (2006) "Guide to Reform of Higher Education: A European Perspective" Economic Policy 21 (47), 535 - 592.

Jurajda, Š. (2005) "Czech Returns to Schooling: Does the Short Supply of College Education Bite?" Czech Journal of Economics and Finance 55 (1-2), pp. 83-95.

Matějů, P., and J. Straková (2005) "The Role of the Family and the School in the Reproduction of Educational Inequalities in the Post-Communist Czech Republic," British Journal of Sociology of Education 26 (1), pp. 17-40. 
McCarl, B.A. (1993) "Citations and Individuals: First Authorship Across the Alphabet," Review of Agricultural Economics 15: 307-312.

Moldanová, D. (2004) Naše přijmení [Our Surnames], Pankrac, Prague, 2nd edition.

Münich, D., Svejnar, J., and K. Terrell (2005) "Returns to Human Capital from the Communist Wage Grid to Transition: Retrospective Evidence from Czech Micro Data," Review of Economics and Statistics 87 (1), 100-123.

Münich, D. (2004) "School Quality and Student Choice," mimeo, CERGE-EI.

OECD (2004) Education at a Glance, OECD, Paris.

UIV - Ústav pro informace ve vzdělávání [Institute for Information on Education] (1999) Školství na křižovatce [Education System at a Crossroad], Prague.

van Ours, J., and V.A. Ginsburgh (2003) "Expert Opinion and Compensation: Evidence from a Musical Competition," American Economic Review 93 (1), 289-296.

van Praag, C.M., and B.M.S. van Praag (in press) "First Author Determinants and the Benefits of Being Professor A (and not Z): An Empirical Analysis of Non-Alphabetic Name Ordering among Economics Authors" Economica.

Šimíková, I., Navrátil, P., and J. Winkler (2004) "Hodnocení programů zaměřených na snižování rizika sociálního vyloučení romské komunity," [Evaluation of programs aiming at lowering the risk of social exclusion of the Roma minority], Research Institute for Labour and Social Affairs, Prague and Brno. 


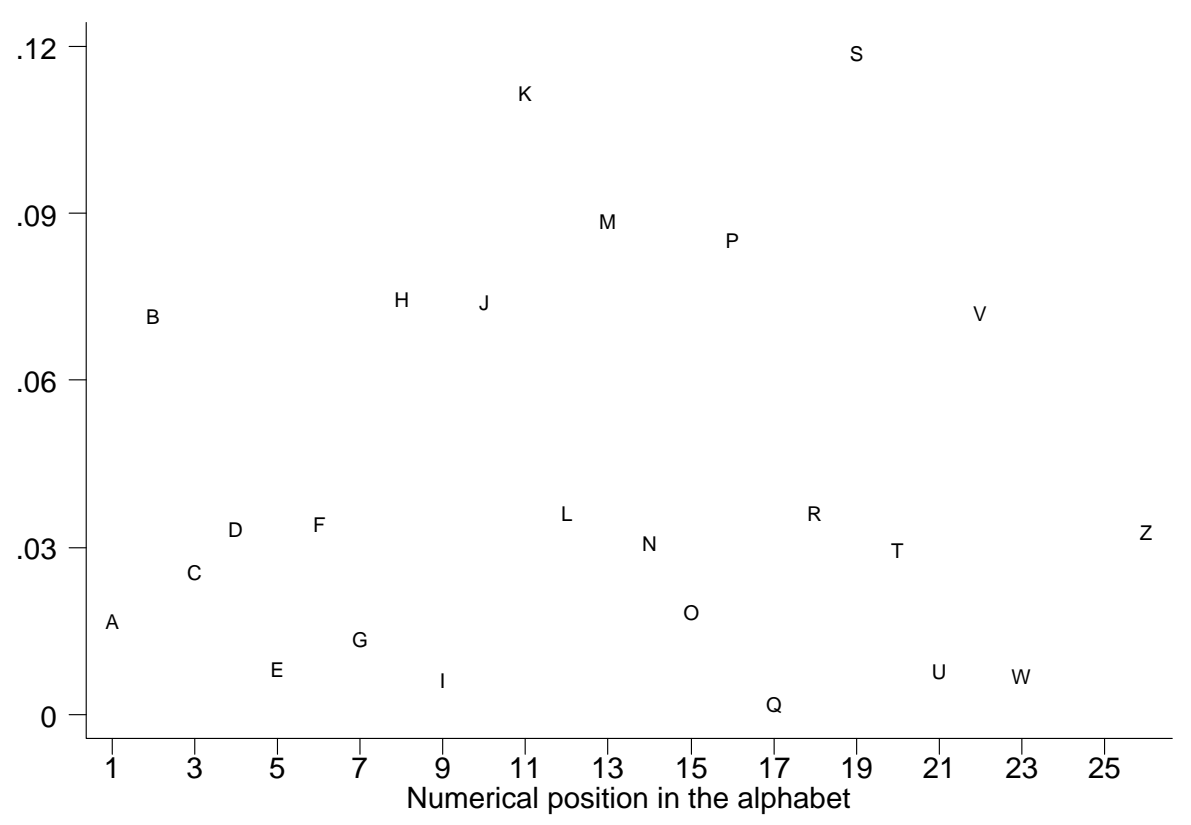

Figure 1: Distribution of Last Name Initials

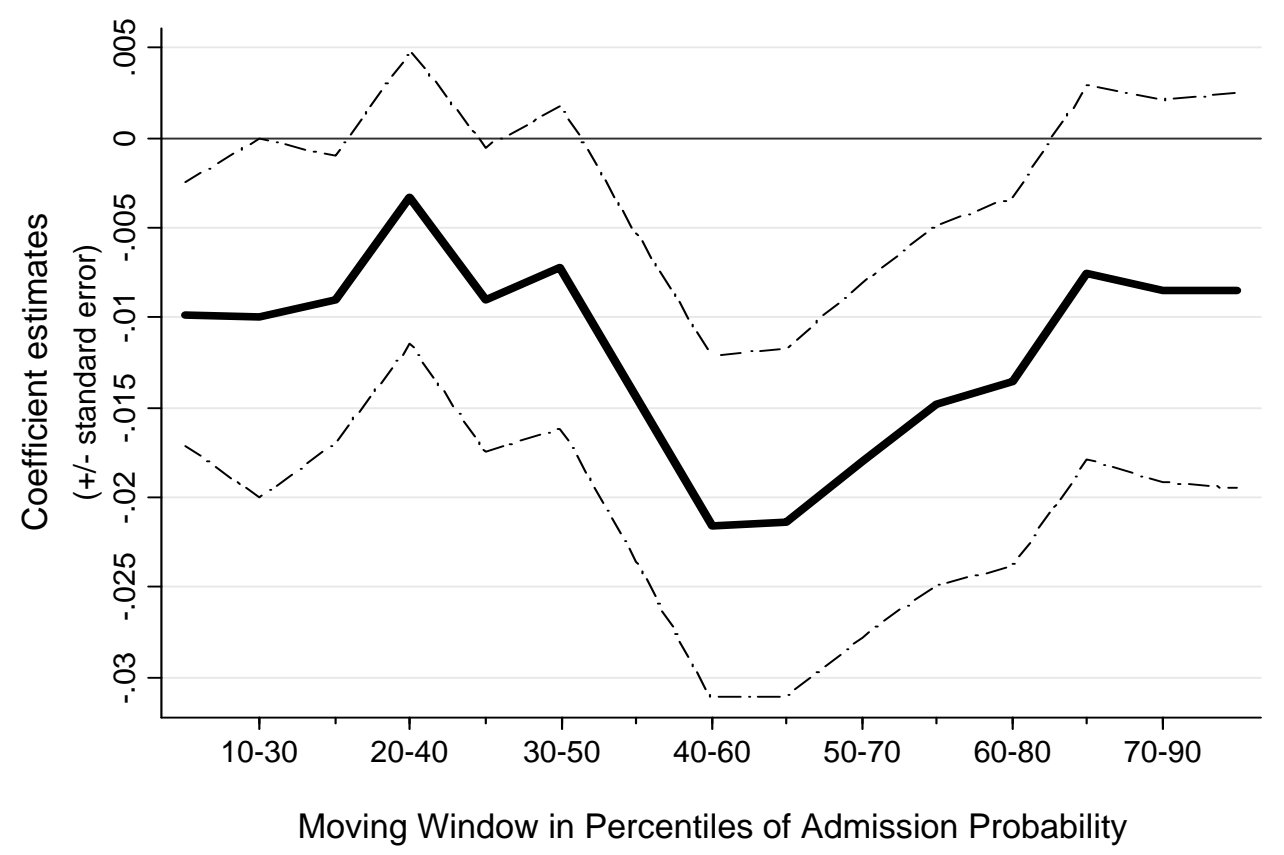

Figure 2: Last-Name Initial Coefficients Across Predicted Admission Distribution 


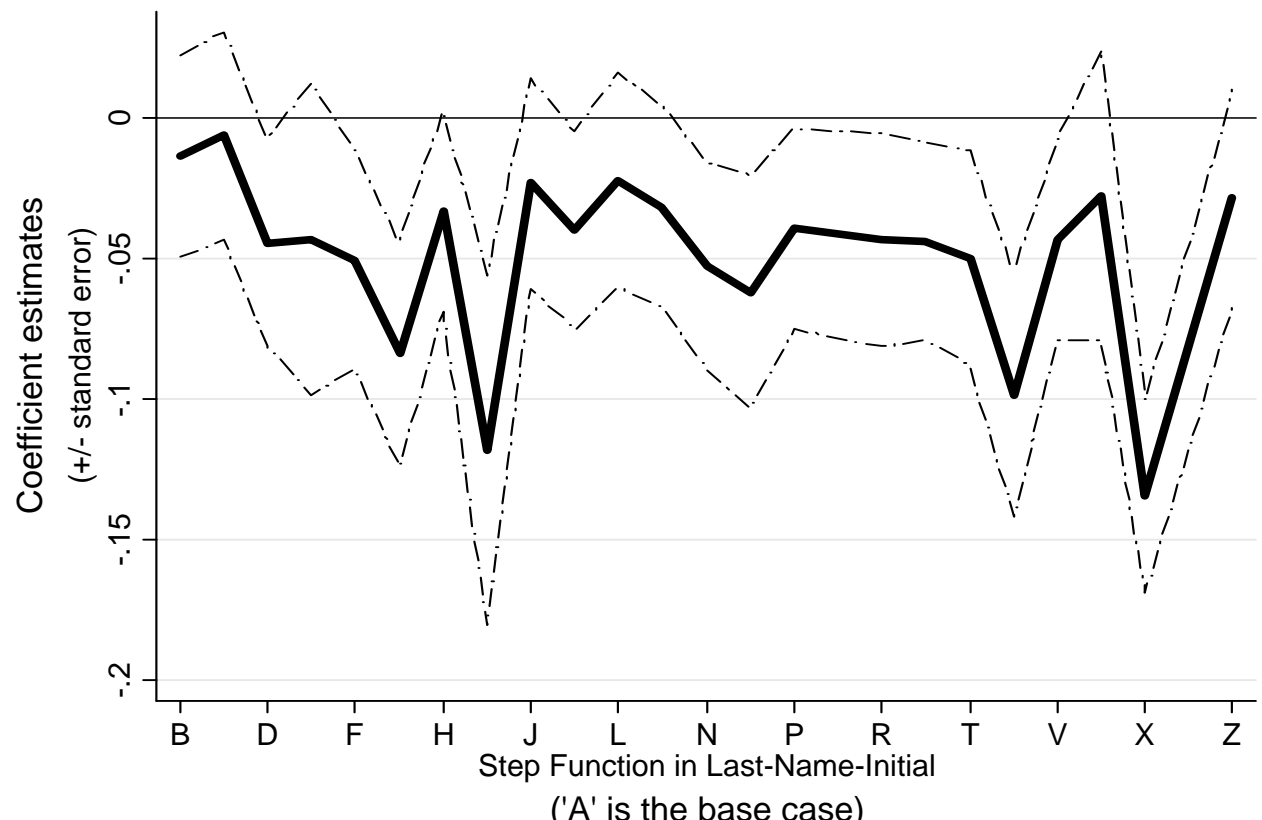

Figure 3: Non-Parametric Specification for the 40-60 Percentile Range

Table 1: Mean Test Scores and Excess Demand by School Type

\begin{tabular}{|c|c|c|c|}
\hline School Type & Academic & Specialized & Apprenticeship \\
\hline \multirow[t]{2}{*}{ Mathematics test score } & 46.3 & 26.6 & 22.7 \\
\hline & $(16.2)$ & $(15.0)$ & $(10.5)$ \\
\hline \multirow[t]{2}{*}{ Czech language test score } & 74.0 & 58.8 & 51.9 \\
\hline & $(11.8)$ & $(12.3)$ & $(11.4)$ \\
\hline Share of female students & 0.58 & 0.59 & 0.43 \\
\hline $\mathrm{N}$ & 19,448 & 50,922 & 26,699 \\
\hline \multirow[t]{2}{*}{ District Excess Demand* } & 0.31 & 0.24 & 0.15 \\
\hline & $(0.15)$ & $(0.19)$ & $(0.24)$ \\
\hline
\end{tabular}

Note: Standard deviations in parentheses.

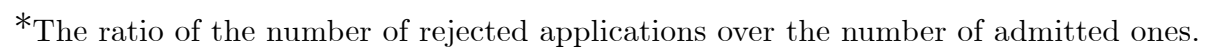


Table 2: Mathematics Test Score Regressions

\begin{tabular}{ccccc}
\hline \hline School Type & All & Academic & Specialized & Apprenticeship \\
& $(1)$ & $(2)$ & $(3)$ & $(4)$ \\
\hline \multicolumn{5}{c}{ Alphabet Position Measure Based on Letters' } \\
Last Initial & $\mathbf{0 . 7 4 8}$ & $\mathbf{2 . 5 1 4}$ & 0.032 & 0.049 \\
& $(0.241)$ & $(0.678)$ & $(0.293)$ & $(0.228)$ \\
First Initial & -0.040 & 0.692 & -0.515 & 0.274 \\
& $(0.168)$ & $(0.523)$ & $(0.300)$ & $(0.293)$ \\
\hline Alphabet Position Measure Based on Population-Distribution Order \\
Last Initial & $\mathbf{0 . 5 6 6}$ & $\mathbf{2 . 0 3 3}$ & 0.198 & 0.006 \\
& $(0.231)$ & $(0.597)$ & $(0.259)$ & $(0.228)$ \\
First Initial & -0.167 & 0.233 & $\mathbf{- 0 . 5 6 6}$ & -0.273 \\
& $(0.146)$ & $(0.417)$ & $(0.237)$ & $(0.213)$ \\
\hline $\mathrm{N}$ & 91,599 & 19,174 & 48,594 & 23,829 \\
\hline \hline
\end{tabular}

Note: Robust standard errors allow for clustering at the last-initial level. Bolded coefficients are statistically significant at the $5 \%$ level. Each regression also controls for students' gender, a Prague dummy, and school-type dummies. 
Table 3: Czech Language Test Score Regressions

\begin{tabular}{|c|c|c|c|c|}
\hline School Type & $\begin{array}{l}\text { All } \\
(1)\end{array}$ & $\begin{array}{c}\text { Academic } \\
(2)\end{array}$ & $\begin{array}{c}\text { Specialized } \\
(3)\end{array}$ & $\begin{array}{c}\text { Apprenticeship } \\
(4)\end{array}$ \\
\hline \multicolumn{5}{|c|}{ Alphabet Position Measure Based on Letters' Numerical Order } \\
\hline \multirow[t]{2}{*}{ Last Initial } & 0.465 & 0.940 & 0.263 & 0.474 \\
\hline & $(0.204)$ & $(0.482)$ & $(0.247)$ & $(0.356)$ \\
\hline \multirow[t]{2}{*}{ First Initial } & -0.312 & -0.303 & -0.548 & 0.173 \\
\hline & $(0.209)$ & $(0.328)$ & $(0.315)$ & $(0.448)$ \\
\hline \multicolumn{5}{|c|}{ Alphabet Position Measure Based on Population-Distribution Order } \\
\hline \multirow[t]{2}{*}{ Last Initial } & 0.381 & 0.869 & 0.190 & 0.363 \\
\hline & $(0.185)$ & $(0.375)$ & $(0.147)$ & $(0.311)$ \\
\hline \multirow[t]{2}{*}{ First Initial } & -0.340 & -0.341 & -0.537 & -0.061 \\
\hline & $(0.265)$ & $(0.209)$ & $(0.237)$ & $(0.310)$ \\
\hline $\mathrm{N}$ & 91,599 & 19,174 & 48,594 & 23,829 \\
\hline
\end{tabular}

Note: See notes to Table 2. 
Table 4: Test Score Regressions with Excess-Demand Interactions

\begin{tabular}{rcccc}
\hline \hline Test Type & Mathematics & Czech & Mathematics & Czech \\
School Type & All & All & Academic & Academic \\
& $(1)$ & $(2)$ & $(3)$ & $(4)$ \\
\hline Alphabet Position Measure Based on Letters' & Numerical Order & \\
Last Initial * Excess Demand & $\mathbf{2 . 3 3 9}$ & $\mathbf{1 . 2 7 2}$ & $\mathbf{6 . 8 1 7}$ & $\mathbf{2 . 6 3 0}$ \\
& $(0.708)$ & $(0.568)$ & $(1.637)$ & $(1.122)$ \\
First Initial * Excess Demand & 1.010 & -1.181 & 2.241 & -1.267 \\
& $(0.823)$ & $(0.909)$ & $(1.175)$ & $(1.634)$ \\
\hline Alphabet Position Measure Based on Population-Distribution Order \\
Last Initial * Excess Demand & $\mathbf{1 . 7 3 8}$ & $\mathbf{1 . 0 7 5}$ & $\mathbf{5 . 4 2 1}$ & $\mathbf{2 . 3 5 8}$ \\
& $(0.687)$ & $(0.481)$ & $(1.519)$ & $(0.876)$ \\
First Initial * Excess Demand & 0.236 & -1.185 & 0.965 & -1.129 \\
& $(0.456)$ & $(0.703)$ & $(1.445)$ & $(1.190)$ \\
\hline \hline
\end{tabular}

Note: See notes to Table 2. The excess demand measure is the ratio of the number of rejected applications over the number of admitted ones. 
Table 5: University Admission Regressions

\begin{tabular}{ccccc}
\hline \hline & All Applications & Percentile Rank $\leqq 40$ & Pct Rank 40-60 & Pct Rank $\geqq 60$ \\
& $(1)$ & $(2)$ & $(3)$ & $(4)$ \\
\hline \multirow{5}{*}{ Last Initial } & -0.006 & -0.001 & $\mathbf{- 0 . 0 2 6}$ & -0.009 \\
& $(0.002)$ & $(0.000)$ & $(0.012)$ & $(0.009)$ \\
First Initial & -0.002 & -0.006 & -0.006 & -0.001 \\
& $(0.006)$ & $(0.0003)$ & $(0.016)$ & $(0.015)$ \\
\hline
\end{tabular}

Alphabet Position Measure Based on Population-Distribution Order

\begin{tabular}{ccccc} 
Last Initial & -0.005 & -0.001 & $\mathbf{- 0 . 0 2 2}$ & -0.008 \\
& $(0.005)$ & $(0.006)$ & $(0.009)$ & $(0.008)$ \\
\multirow{3}{*}{ First Initial } & -0.005 & -0.007 & -0.004 & -0.005 \\
& $(0.005)$ & $(0.005)$ & $(0.011)$ & $(0.011)$ \\
\hline
\end{tabular}

Alphabet Position Measure Based on Faculty-Specific-Distribution Order

\begin{tabular}{lcccc} 
Last Initial & -0.005 & -0.002 & $\mathbf{- 0 . 0 2 2}$ & -0.007 \\
& $(0.005)$ & $(0.005)$ & $(0.009)$ & $(0.008)$ \\
First Initial & -0.006 & -0.008 & -0.005 & -0.007 \\
& $(0.005)$ & $(0.005)$ & $(0.009)$ & $(0.008)$ \\
\hline $\mathrm{N}$ & 116,479 & 46,059 & 22,890 & 47,530 \\
\hline \hline
\end{tabular}

Note: Robust standard errors allowing for clustering of unobservables at the last-initial level are in parentheses. Bolded coefficients are statistically significant at the $5 \%$ level. Columns (2) to (4) correspond to different parts of the predicted faculty-specific admission-probability distribution, which is based on student and school characteristics. Each regression additionally controls for a step function in faculty-specific excess demand (oversubscription). 
Table 6: Log Wage Regressions

\begin{tabular}{lccc}
\hline \hline & Whole Sample & Less Selective Schools & Highly Selective Schools \\
& $(1)$ & $(2)$ & $(3)$ \\
\hline \multirow{2}{*}{ Last Initial } & 0.039 & 0.056 & -0.049 \\
& $(0.036)$ & $(0.037)$ & $(0.120)$ \\
First Initial & 0.012 & -0.003 & 0.083 \\
& $(0.040)$ & $(0.041)$ & $(0.126)$ \\
\hline & Alphabet Position Measure Based on Letters' Numerical Order & -0.009 \\
Last Initial & 0.042 & $\mathbf{0 . 0 5 2}$ & $(0.099)$ \\
& $(0.030)$ & $(0.031)$ & 0.060 \\
First Initial & 0.011 & -0.001 & $(0.089)$ \\
& $(0.029)$ & $(0.030)$ & 285 \\
\hline $\mathrm{N}$ & 1,852 & 1,567 & Measure Based on Population-Distribution Order \\
\hline \hline
\end{tabular}

Note: Bolded coefficients are statistically significant at the $10 \%$ level. Robust standard errors in parentheses.

Additional controls are years of education, experience, its square, and a Prague dummy. 